\title{
AS APRESENTAÇÕES DE PACIENTE SOB A LÓGICA DOS DISCURSOS
}

CRISTIANA MIRANDA RAMOS FERREIRA ${ }^{\text {; }}$; Orcid: https://orcid.org/0000-0001-8181-293X JESUS SANTIAGO ${ }^{2}$

${ }^{1}$ Universidade Federal de Minas Gerais (UFMG), Programa de Pós-Graduação em Psicologia, Departamento de Psicologia,.Belo Horizonte/MG, Brasil.
RESUMO: O presente artigo analisa a prática da apresentação de pacientes enquanto um dispositivo que, ao longo de sua história, foi operado por diferentes discursos. Na medida em que cada discurso implica em diferentes articulações entre seus elementos estruturantes: paciente, apresentador e público; isso repercutiu no uso diferentes técnicas e estratégias de intervenção, assim como no papel destinado à apresentação no tratamento e/ou no ensino.

Palavras-chave: apresentação de pacientes; discursos; psicanálise; psiquiatria.

Abstract: Presentations of patient under the discourses's logic. This article examines the practice of patient presentation as an apparatus that, throughout its history, has been operated by different discourses. To the extent that each speech implies different articulations between its structural elements: patient, presenter and public that affected the use of different techniques and intervention strategies, as well as on paper intended for presentation in the treatment and/or teaching.

Keywords: Presentation of patients; discourses; psychoanalysis; psychiatry.

DOI - http://dx.doi.org/10.1590/S1516-14982019001011

Todo o conteúdo deste periódico, exceto onde estiver identificado, está licenciado sob uma licença Creative Commons (cc by 4.0). 
$\mathrm{P}$ ara se pensar a prática da apresentação de pacientes é preciso, inicialmente, levar em consideração que isso que se anuncia como uma atividade única refere-se, em verdade, a uma diversidade de experiências. Entendemos que o que possibilitou manter reunidas práticas tão diversas, sob esta mesma nomeação "apresentação de pacientes", foi antes o seu aspecto estático, estruturado na presença de três elementos distintos: paciente, público e entrevistador. A esse mecanismo estruturante, que dá aparente unicidade a este aparelho de intervenção, chamaremos de "dispositivo"1, enquanto que à sua dimensão viva, dinâmica, referido à pluralidade de práticas que se pode produzir quando esse dispositivo é posto em movimento, chamaremos de "discurso".

Fazemos aqui referência aos quatro discursos: Discurso do Mestre, Discurso Histérico, Discurso do Analista e Discurso Universitário, conforme propostos por Lacan em O Seminário, Livro 17: O avesso da Psicanálise (1969-70/1992).

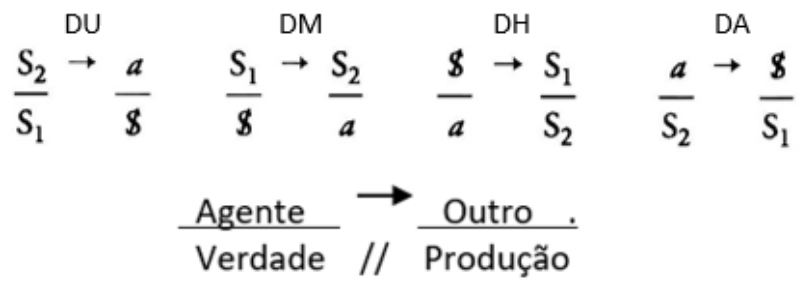

Nossa hipótese é que, ao longo de sua história, a psiquiatria foi, em cada época, orientada prioritariamente por um dos quatro discursos, o que incidiu sobre a prática da apresentação de pacientes, tanto no que diz respeito às técnicas e estratégias de intervenção, assim como no papel a ela destinado no tratamento e/ou no ensino psiquiátrico.

Para pensarmos o efeito dos diferentes discursos sobre a prática das apresentações, propomos dividir as abordagens da psiquiatria sob três perspectivas, estabelecidas a partir da importância dada à fala do paciente. A primeira perspectiva seria a da psiquiatria clássica, caracterizada pela utilização do "método clínico de observação" pautado na descrição detalhada dos fenômenos, que encontrava na fala do paciente o seu principal meio para definição de diagnóstico e prognóstico do caso em questão, assim como para a constituição de saber psiquiátrico de uma forma geral. Teríamos, como marco desse período clássico, o ano de 1783, quando Philippe Pinel assumiu a direção de Bicêtre, soltando os loucos de suas amarras, até 1934, ano da morte de Clérambault, considerado último dos grandes clássicos (BARRETO, 2013).

Como segunda perspectiva, teríamos uma psiquiatria caracterizada pelo abandono do método clínico de observação em favor do pragmatismo terapêutico. Essa psiquiatria, que chamaremos psiquiatria "biologicista", começou a ganhar força por volta dos anos 20, destacando-se pelo centramento de suas investigações nas intervenções ao nível do corpo, com crescente desinteresse pela fala do paciente e pela precisão diagnóstica. Mas foi particularmente a partir da segunda metade do século XX, com o avanço da neuroquímica, que esta psiquiatria alcançou a hegemonia, dominando o campo psiquiátrico até os dias de hoje (SALIM, 1987).

Por fim, como terceira perspectiva, a psicanálise, mais especificamente a abordagem lacaniana, caracterizada pela aposta radical na palavra como forma de permitir aceder ao sujeito do inconsciente, ao sujeito do gozo.

\section{O DISCURSO DO MESTRE E O INTERROGATÓRIO CLÁSSICO}

Em seu momento inaugural, a psiquiatria, que nascia sob a influência da concepção pineliana, tomava a

\footnotetext{
${ }^{1}$ Dispositivo: referente à disposição (arranjo, distribuição), que prescreve, que ordena (HOUAISS, 2001).
} 
loucura enquanto uma doença das atividades mentais, cujas intervenções se sustentavam na confrontação das ideias delirantes do paciente com a realidade, no intuito de demovê-las. Como esclarece Foucault (2006), dentre os precários recursos terapêuticos da época, destacou-se a prática do interrogatório. O interrogatório se sustentava na produção da crise: o paciente era pressionado, provocado, de forma a tornar visíveis os seus fenômenos, como, por exemplo, seus delírios e alucinações, fazendo revelar sua realidade delirante, permitindo sua confrontação com a realidade compartilhada, representada pela figura do médico, ao qual o paciente deveria, por fim, se submeter. Esse procedimento permitia, a um só tempo, o tratamento, pois se acreditava que levar o paciente a reconhecer sua loucura, e consentir com a verdade do médico, era o primeiro passo para a cura, mas permitia, também, a investigação da doença mental de um modo geral, visto que era através dos relatos dos pacientes que se podia destrinchar isto que se apresentava sob a forma de uma multiplicidade caótica de sintomas, diferenciando-os, descrevendo-os, ordenando-os, classificando-os. 0 interrogatório se efetivava, portanto, na articulação entre a pesquisa e a clínica.

Quanto à apresentação de pacientes, podemos dizer que esta nada mais era que o interrogatório realizado diante de um público composto pelo corpo clínico institucional (profissionais e residentes), articulando, aí, a dimensão de ensino (FOUCAULT, 2006). Portanto, se a apresentação de pacientes surge, desde o início do século XIX, frente à demanda de ensino da psiquiatria, sua dimensão didática nasce marcadamente associada à dimensão clínica, até mesmo porque, nesse período inaugural, o que se ensinava, era justamente isso - clínica, ou seja, é que somente através da observação detalhada dos fenômenos, podese elaborar bem um diagnóstico e avaliar o prognóstico de um caso.

Assim, na psiquiatria clássica, em função de sua própria perspectiva investigativa, baseada no detalhe e efetivada na confrontação do paciente pelo médico, nos parece pertinente pensarmos que as apresentações se davam orientadas, sobretudo, pelo discurso do mestre. Quando dizemos "sobretudo" é no sentido de assinalar que determinada prática social se funda prevalentemente em um discurso, o que não impede que se lance mão de outros discursos, enquanto estratégia para se alcançar seu objetivo último. Não se pode dizer nem de síntese entre os discursos, nem da relação de causa e efeito, mas de uma dinâmica em função daquilo que ocupa o lugar da verdade. Assim, ainda que, em uma apresentação, o apresentador possa se utilizar de mais de um discurso, tomamos como prevalente aquele sob a luz do qual os impasses são decididos.

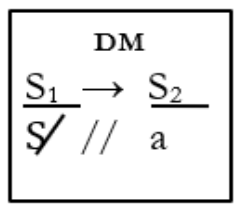

Nessa perspectiva, o psiquiatra clássico, ao conduzir a apresentação de pacientes, o fazia prioritariamente a partir do discurso do mestre. Agenciava o discurso identificado ao $\mathrm{S}_{1}$, ou seja, posicionavase como sendo, de fato, o senhor e mestre da loucura, provocando a crise no paciente. Certamente que ele era efetivo nisso. Afinal, como nos esclarece Beneti (1994), a partir do matema do automatismo mental ( $\left.a / \mathrm{S}_{2}\right)$, ao psicótico cabem duas posições no que diz respeito ao saber do Outro: ou ele se encontra na posição de $a$, enquanto objeto de gozo do saber do Outro, ou se apresenta enquanto $S_{2}$, como uma máquina de significar delirantemente. Se, na apresentação, o paciente entra na posição de objeto em relação ao mestre, ao senhor do asilo, na medida em que ele é interrogado, confrontado, provocado, isso acaba por abalar sua convicção psicótica quanto à existência de um Outro consistente, dividindo-o, colocando-o frente ao insuportável, o que o desestabiliza, empurrando-o ao surto. Desalojado de sua posição de objeto, só lhe restaria o trabalho de significação delirante como possibilidade para restaurar sua certeza. Ou seja, o psiquiatra clássico, ao desestabilizar o paciente, para produzir aquilo que ele acreditava ser as provas da loucura, sem o saber, ele colocava em cena a operação psicótica de tratamento do real que o invade. Dessa forma, como assinala Moura: "do escravo é extraído o fundamental para que esse saber-fazer se torne saber do senhor" (MOURA, 
2010, p. 57). Assim, o saber do psicótico $\left(S_{2}\right)$ era transferido para o mestre, que dele se apropriava ao nomear seus sintomas, ordenando-os e classificando-os em síndromes e quadros nosológicos, estabelecendo seus mecanismos, produzindo, então, um saber sobre a loucura.

Como produto $(a)$ dessa operação, podemos dizer, de dominação, $\left(S_{1} \rightarrow S_{2}\right)$, ao Ihe dar significação, ao imprimir-Ihe um diagnóstico, o psiquiatra se satisfaz na produção da doença (a). Contudo, o que o discurso do mestre produz é um objeto que não está articulado com o sujeito. A disjunção, sempre presente entre a produção e a verdade $(\$ / / a)$, revela-se no desconhecimento acerca das questões fundamentais do sujeito, pois o diálogo é com a doença e não com o sujeito. Por mais que o paciente apresente seus fenômenos, seu delírio, suas alucinações, e por mais que o mestre produza saber sobre seus sintomas, o psiquiatra não consegue captar a dimensão do real posto em jogo na psicose. Dessa forma, a verdade (\$) sempre oculta é que, se o psiquiatra clássico crê dominar a loucura, se produz saber sobre as diferentes formas da doença, todavia a essência da loucura lhe escapa. Se toma os sintomas que produz como prova da doença, contudo, ignora a verdade do sintoma. Ignora sua causa, assim como desconhece a incidência de sua própria posição no discurso sobre a crise que provoca.

Mas é preciso considerar que, para além da dimensão clínica, a apresentação tinha também uma intenção de ensino, o que nos leva a interrogar o deslocamento do discurso do mestre para o discurso universitário. Como a própria situação da psiquiatria clássica não era muito favorável à permanência no discurso universitário, visto que a disciplina que ensinava estava em construção, temos que era a operação a partir do discurso do mestre que, ao dar visibilidade aos fenômenos psíquicos, conformava então as condições para o discurso universitário, exigindo permanentemente que o apresentador retirasse o foco dos alunos para centrá-lo novamente no paciente, restabelecendo o discurso do mestre. Nesse sentido, o discurso universitário seria um prolongamento do discurso do mestre (RABINOVICH, 2001).

Só teremos a prevalência do discurso universitário, como principal operador do dispositivo da apresentação de pacientes, a partir do final do século XIX, início do século XX, período marcado pela decadência da psiquiatria clássica e início de sua supressão pela psiquiatria biologicista (FERREIRA, 2013). Sobre sua decadência, um primeiro aspecto que cabe ressaltar é que essa perspectiva clínica das descrições minuciosas da investigação precisa tão cara aos alienistas ávidos por captar, identificar, descrever e diferenciar entidades mórbidas não condizia com sua eficácia terapêutica, praticamente inexistente, o que lançou certo descrédito sobre essa prática. Um segundo aspecto que também contribuiu para sua decadência foi o esgotamento das possibilidades descritivas do método clínico, que chegara ao seu limite. Após um século e meio de investigações, a psiquiatria já construíra certo saber tanto sobre os fenômenos quanto sobre as síndromes e doenças, o que permitiu o abandono de seu caráter investigativo para se acomodar num saber já constituído. Assim, se, na psiquiatria clássica, seja na clínica, seja na apresentação da pacientes, a

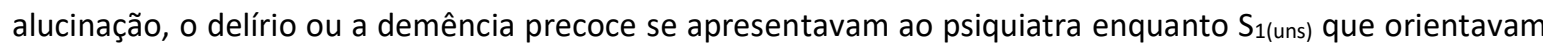
suas investigações, na medida em que o saber sobre isso já se encontra formatado, constituído, é do lugar de $S_{2}$ que estes irão se anunciar. É por já saber o que é uma alucinação, um delírio, uma demência, que o alucinado, o delirante, o demente, serão tomados enquanto objeto de ensino, para ilustrar uma aula ou uma conferência sobre o tema. Logo, se já não há o que descobrir, é do lugar de saber $\left(\mathrm{S}_{2}\right)$ que os psiquiatras passarão agenciar o dispositivo da apresentação, ou seja, do discurso universitário.

\section{DISCURSO UNIVERSITÁRIO E A UNIVERSALIZAÇÃO DO SABER}

No início do século $X X$, o que se percebe é o desenvolvimento de uma psiquiatria biologicista, caracterizada pela ênfase nas intervenções ao nível do corpo. Não que antes não houvesse intervenção no corpo, haja vista as práticas de tratamento físico, como a "máquina rotatória" de Halaran, de 1818, ou a ducha, como oficializada por Morrison, em 1828 (PESSOTTI, 1996), entre muitos outros. Contudo, na psiquiatria 
clássica, tais terapêuticas eram aplicadas numa perspectiva que oscilava entre a coerção e a punição, visando, em última instância, à adequação do paciente. Já para a psiquiatria que então começa a despontar, o interesse está focado na intervenção em si e seus efeitos sobre o corpo do paciente, o que independe da fala do paciente ou de suas particularidades reveladas no relato do caso.

Como primeiros avanços dessa psiquiatria biologicista, podemos citar a invenção de métodos tais como a malarioterapia (1917), a lobotomia (1935) e o eletrochoque (1937), (SALIM, 1987). Nas décadas de 50/60, com o avanço da psicofarmacologia, esta se tornará hegemônica, posição que se perpetua até o momento atual. Essa psiquiatria biologicista, oficializada hoje na lógica classificatória do DSM-IV e do CID-10, não se interessa pelo paciente no que este poderia apresentar de particular, na medida em que está orientada pelo saber pré-existente ao doente. O interrogatório, paradigma da psiquiatria clássica, perde seu lugar de importância. Essa psiquiatria, que abriu mão da clínica, trata o doente como aquele que é preciso fazer calar, pois tudo que é subjetivo é visto como perturbador ao modelo da universalização, da quantificação, numa tentativa permanente de aprender o real, sem que nada escape. Como assinala Ferreira, "diferenciar a idéia delirante da deliróide; uma alucinação verdadeira e uma pseudo-alucinação, torna-se supérfluo, já que os antipsicóticos irão atuar sobre esses sintomas do mesmo jeito" (FERREIRA, 2002, p. 16). Afinal, para operar com essa psiquiatria, poucos parâmetros são suficientes para atender ao modelo estatístico do DSM-IV e CID10, que visa, em última instância, à medicação. Em lugar de se debruçar sobre os enigmas da loucura, o psiquiatra vai encontrar respostas nos protocolos e guidelines.

Este reducionismo sofrido pela psiquiatria, principalmente a partir do final do século XX, será sentido também na prática da apresentação. Nas apresentações realizadas sob a lógica da psiquiatria contemporânea, ancorada prioritariamente no discurso universitário, o que vemos é o psiquiatra ocupar cada vez mais a posição de detentor do saber $\left(S_{2}\right)$, de um saber já constituído sobre a doença. Podemos dizer, portanto, que não foi o uso do discurso universitário que levou ao declínio da apresentação de pacientes, mas, ao contrário, foi o empobrecimento clínico da psiquiatria, o desinteresse pela investigação e pela particularidade do caso, que possibilitou a proeminência desse discurso. Da mesma forma que a psiquiatria clássica era compatível com o discurso do mestre, essa psiquiatria biologicista mostrou grande afinidade com o discurso universitário.

$$
\begin{array}{|c|}
\mathrm{S}_{2} \\
\frac{\mathrm{S}}{\mathrm{S}_{1}}
\end{array}
$$

Nesse discurso, o entrevistador, encarnação do todo-saber $\left(\mathrm{S}_{2}\right)$, toma o Outro $(a)$, seja o paciente, seja o aluno, como objeto sobre o qual o aplica seu saber prévio, sem se dar conta que é gozado pelo saber do mestre $\left(S_{1}\right)$, que de fato constituiu o saber que o orienta. Dizemos de um saber preexistente visto tratar-se de um saber já constituído sobre a doença - referência para enquadrar e classificar os signos manifestados pelo doente. Vê-se aqui que o foco é a doença. O paciente, cuja fala desperta pouco ou quase nenhum interesse, é tomado na posição de objeto a ser exposto aos alunos, como exemplo dos sintomas evidentes, síndromes e transtornos em questão. É o que nos descreve Gurgel, tomando como referência uma entrevista realizada em uma faculdade de medicina. O professor catedrático de psiquiatria segura o braço do paciente em distintas posições e comenta: "Trata-se de um catatônico típico!... Vejam a flexibilidade cérea, sua postura robótica... sua atitude autista" (GURGEL, 2005). Como bem observa Gurgel, o paciente é tomado "na posição de objeto, como exemplo de uma patologia previamente descrita e classificada, que visa a história da doença, o diagnóstico diferencial e a comprovação de um saber construído sobre a doença" (idem).

Entretanto, a verdade oculta no discurso universitário é que esse psiquiatra/professor que tudo sabe $\left(\mathrm{S}_{2}\right)$ ignora a origem de seu saber $\left(\mathrm{S}_{1}\right)$. Se repete, se reproduz os mestres, ele o faz desconectado da riqueza clínica que, em última instância, possibilitou a elaboração dos manuais de classificação que operam com um saber reduzido, efeito da homogeneização, da universalização do saber. Portanto, numa posição muito diferente do 
mestre clássico, que buscava saber sobre os detalhes do caso para elaborar um diagnóstico e decidir um prognóstico, o psiquiatra contemporâneo conta com um saber pronto, prescritivo, cujas diretrizes do tratamento já se encontram definidas nos guidelines e protocolos próprios. Isto se dá porque "o saber, aí, é encarnado por um mestre que o transmite como resposta, não como questão" (RODRIGUES, 2010, p. 119). Assim, ele não mais interage com o paciente, ele não produz a crise e, se recolhe os sinais e sintomas mais evidentes, é apenas para inseri-los na ordem já estabelecida.

Como produto desse enlaçamento entre o agente e o Outro $\left(S_{2} \rightarrow a\right)$, temos alunos e pacientes $(\$)$ gozados pelo saber do psiquiatra. Quanto ao paciente, antes fonte de saber, passa a ser tratado enquanto um sujeito destituído de qualquer subjetividade, reduzido a material de ilustração da disciplina ensinada. Com relação aos alunos, receptáculos desse saber standartizado $(a)$, o que se produz é a angústia diante de sua impotência, pois, se aprende a nomear, classificar, medicar, contudo não sabe de fato tratar o real de gozo ao qual o psicótico se encontra submetido. Essa divisão produzida pode apontar para duas direções: por um lado, para a universalização do sujeito, resposta própria aos psiquiatras/alunos que, não querendo saber de sua própria divisão, obturam sua angústia ancorando-se nas respostas-padrão, alienando-se neste saber imposto, preferindo ignorar o gozo que os afetam. Por outro lado, o sujeito em crise com o saber totalizante, angustiado frente à incapacidade de responder às exigências práticas do que fazer com o louco, pode apontar para o discurso histérico, que se insurgirá contra o saber estabelecido, desmascarando a objetificação do doente pela ciência e questionando o saber e a prática psiquiátrica.

Embora restrita à dimensão didática e empobrecida pela própria perspectiva reducionista e universalizante da psiquiatria que representava, a prática das apresentações desse período seguia tendo importância como instrumento de ensino. As apresentações de paciente continuaram, portanto, como prática regular nos hospitais psiquiátricos da época, até por volta das décadas de $60 / 70$, quando se farão sentir as influências do discurso do analista e do discurso histérico.

\section{O DISCURSO DO ANALISTA E A CLÍNICA DO SUJEITO}

Felizmente, a história não é linear. Assim, os anos 20 e 30 ao mesmo tempo em que foram palco da emergência dessa psiquiatria biologicista, que alcançará a hegemonia a partir dos anos 50 em função do avanço da psicofarmacologia testemunharam também as últimas manifestações da então moribunda psiquiatria clássica. Assim, em meio às apresentações "didáticas", destacaram-se as concorridas apresentações de paciente realizadas por Clérambault (FERREIRA, 2006).

Considerado o último dos grandes clássicos, as apresentações de Clérambault seguiam a lógica do interrogatório (CLÉRAMBAULT, 2004). Orientado pelo discurso do mestre, Clérambault ensinava clínica: uma clínica da investigação, da minúcia, do interesse no particular. Uma clínica para a qual importava, por exemplo, verificar se o paciente reagia a partir de uma interpretação ou de uma imaginação, se se tratava de um perseguidor-perseguido não amoroso ou um erotômano convertido em perseguidor, visto que era nos detalhes do caso que se definia o diagnóstico diferencial, o prognóstico do paciente e, portanto, seu destino.

Foram estas as apresentações que marcaram Lacan. E ele é explícito em reconhecer que sofreu influências de Clérambault, seu "único mestre na observação dos enfermos" (LACAN, 1989b, p. 169). Foi também na década de 30, ainda psiquiatra, que Lacan iniciou suas apresentações que, como ele mesmo disse, consistiam na prática de dar a palavra a seus pacientes.

Todavia, ele o fez de uma posição muito diferente do mestre, pois, ao ser "aspirado para a psicanálise" (LACAN, 1972), é do lugar de analista que, como ele mesmo dirá, ele irá conduzir suas apresentações. Temos assim que Lacan tomará, como referência para suas apresentações, as mesmas coordenadas que orientam a clínica psicanalítica, à medida que se fundam sobre "as virtudes da palavra para interagir e agir na clínica de um caso" (SANTIAGO, 2000, p. 81). Ou seja, tratamos aqui do dispositivo da apresentação orientado pelo discurso do analista, visto que este é o único discurso que toma o Outro como sujeito. Em lugar de dominar, 
o que se trata é de dar um lugar ao saber do sujeito, permitindo que algo do singular possa emergir. Como efeito dessa mudança discursiva, temos que as apresentações de Lacan resultaram muito diferentes das apresentações realizadas até então. Em lugar de exibição do paciente, o que seu público podia testemunhar era o encontro de um psicanalista com um sujeito. Como nos diz Léger (2008), duas pessoas conversando normalmente diante de um auditório atento a este colóquio singular.

$$
\stackrel{\text { DA }}{\stackrel{\mathrm{a}}{\mathrm{S}_{2}} / /} \frac{\mathrm{S}}{\mathrm{S}_{1}}
$$

Para começar, teríamos, no lugar do agente, o analista (a). Agenciar o discurso enquanto $a$ é colocar-se na posição de ignorância, esvaziado de saber prévio, seja sobre o doente, seja sobre sua doença - única posição que possibilita o desejo de saber. Se o analista se apresenta como objeto, contudo, não o faz enquanto objeto de gozo, mas como objeto esvaziado de substância gozosa que, justamente por isso, causa um movimento no Outro.

Todavia, como já dissemos, no discurso do analista, no lugar do Outro está justamente o sujeito (\$), portanto, é ele que o analista precisa acionar. É nesse sentido que podemos entender o manejo clínico de Lacan $(a \rightarrow \$)$ que, em suas apresentações, "tentava tocar o sujeito no doente" (LAURENT, 1989, p. 152).

Tomar o sujeito no lugar do Outro é introduzir na apresentação de pacientes a subversão freudiana fundadora da psicanálise, ou seja, reconhecer que há um sujeito no doente. Sujeito este que só poderá ser alcançado através de sua própria fala. É verdade que Freud se endereçava prioritariamente aos neuróticos, enquanto as apresentações de Lacan se davam principalmente com sujeitos psicóticos.

Assim, como produto desse encontro entre um analista e um sujeito psicótico, (a $\rightarrow \$)$, o que se espera é recolher significantes do próprio sujeito $\left(S_{1}\right)$; significantes estes que orientam o gozo do sujeito, na medida em que articulam o real do gozo. Ao analista, cabe deixar-se conduzir por esses significantes, tomando-os como bússola para a direção do tratamento.

De certo que o psicótico não entrega isso de imediato. Ao contrário, é preciso dispô-lo a isso, é preciso dispô-lo a deixar cair sua reticência. Para tanto, como nos instrui Lacan, é preciso não compreendê-lo. Se compreendemos algo, nos detemos aí, mas, se quisermos captar o verdadeiro, o núcleo da questão, então é preciso não compreender. O que aprendemos com Lacan é que a posição do analista é de uma "submissão completa, ainda que advertida, às posições propriamente subjetivas do sujeito" (LACAN, 1998a, p. 540). É essa posição de ignorância, operada a partir do não compreender, que propulsiona o discurso, pois, na medida em que o analista não compreende, o paciente é convidado a falar, o que possibilita que algo novo possa aparecer: seja uma articulação inédita, um significante novo, um neologismo, o momento do desencadeamento...

O que permite essa operação é justamente o lugar que o analista vai ocupar em relação ao saber, visto que, no discurso do analista, o saber $\left(\mathrm{S}_{2}\right)$ ocupa do lugar da verdade. Como sabemos, a verdade é o motor do discurso, e, como nos diz Lacan, "nenhuma evocação da verdade pode ser feita se não for para indicar que ela só é acessível por um semi-dizer, que ela não pode ser inteiramente dita porque, para além de sua metade, não há nada há dizer" (LACAN, 1992, p. 49). Dessa maneira, a operação do analista é sustentada no reconhecimento de que o saber jamais assegura a totalidade do conhecimento, menos ainda sua universalização. De certo que há um saber que sustenta o ato analítico, pois não se trata de qualquer coisa (QUINET, 2006), contudo, o saber, seja sobre a teoria, seja sobre a estrutura psicótica, não recobre as particularidades do caso. Se o diagnóstico permanece uma referência para a direção do tratamento, ele não chega a ser suficiente para a condução do caso, visto que isso só se define na dimensão singular do sujeito. Como esclarece Beneti (1994), em última instância, é a partir da singularidade de cada caso que poderemos 
saber algo dos modos de retorno do gozo, o que irá nos possibilitar algum cálculo clínico ou hipóteses prognósticas.

Mas, como já dissemos, para que esse algo se produza, é preciso dispor o psicótico a isso. Para tanto, o analista deve se colocar em posição de aprender com o psicótico, o que tem como efeito aquilo que Miller ressaltou, do que aprendemos com Lacan: "o ensino dos pacientes nas apresentações de Lacan, é assim que é preciso dizer" (MILLER, 1996, p. 146). E, realmente, é o paciente quem nos instrui não apenas sobre seu caso, mas, se soubermos nos deixar conduzir, é sobre a psicose que podemos aprender.

Portanto, se, na apresentação de pacientes orientada pelo discurso do analista, é o paciente quem ensina, isso nos coloca uma questão acerca da função do apresentador. Podemos dizer que isso coloca o analista em uma posição muito peculiar, pois o fato de entrevistar o paciente diante de um público implica certo compromisso de transmitir algo. Todavia, como ressalta Porge (1996), ele não sabe o que será, visto que isso não lhe pertence, mas ao paciente. Neste caso, o que interessa não é que o paciente possa ilustrar um saber prévio, mas, antes, o que de singular o caso apresenta. Isso porque a apresentação para psicanálise é antes um dispositivo de transmissão, do que um dispositivo de ensino formal. Como afirma Leguil: "O ensino na apresentação repousa na exemplaridade de uma experiência e não, em realidade, na construção fundamentada de um caso" (LEGUIL, 2004, p. 44). Exemplaridade esta, que permite ao público aprender não apenas a partir do dizer do psicótico, mas também a partir da operação do analista com o real posto em jogo nesse encontro.

Segundo Porge, o que se transmite numa apresentação é a própria clínica, no próprio momento em que ela se constitui: "Trata-se de um caso, privilegiado, em que a transmissão da clínica é síncrona ao que é transmitido; em que, por conseguinte, a transmissão é parte integrante da clínica” (PORGE, 2009, p. 224). Acreditamos que, em última instância, o que se trata na apresentação psicanalítica, é dar ao sujeito psicótico a possibilidade de bordejar, de circunscrever o que lhe sucede, de afastar o impossível de suportar a partir de um tratamento pela palavra (LEGUIL, 2004). Contudo, esse é um manejo clínico sempre delicado, pois, se bordejar esse ponto é o que é preciso fazer para apaziguar o gozo, é também o que pode desencadear uma agudização do quadro, sendo necessário ao analista manobrar a transferência a fim de contornar a incidência da fala do sujeito sobre ele mesmo.

Nesse sentido, podemos dizer que, na apresentação orientada pelo discurso do analista, a exposição é antes do apresentador:

Quem se presta a isso em público engaja-se em um teste de capacidade que revela - para os outros e de imediato - a verdade do lugar onde está e dos meios de que se serve, a fim de que sua atitude conjugue a momentânea suspensão de um saber consistente com a pesquisa do que, no outro, funciona como verdade, a fim de que suas maneiras de falar associem a uma não-mestria de fachada uma certeza em uma direção paradoxal, dado que ela é igualmente submissão, docilidade às posições subjetivas do outro. (LEGUIL, 1998, p. 98).

Quanto aos efeitos dessa subversão produzida pelo discurso do analista sobre o dispositivo da apresentação, podemos dizer que isto fez sobressair o caráter clínico da apresentação de paciente, não apenas no que diz respeito à investigação diagnóstica, mas também de intervenção terapêutica.

\section{O DISCURSO HISTÉRICO - REPÚDIO À PRÁTICA DA APRESENTAÇÃO}

Se, até 1960, a apresentação de pacientes se consolidou como uma prática tradicional e freqüente na psiquiatria, é por volta dos anos 60 que esta começa a ser duramente interpelada, podemos mesmo dizer, condenada, pelos movimentos que, como a anti-psiquiatria e a reforma psiquiatra, entre outros, questionavam o saber e a prática psiquiátrica, de uma maneira geral (FOUCAULT, 1979). 


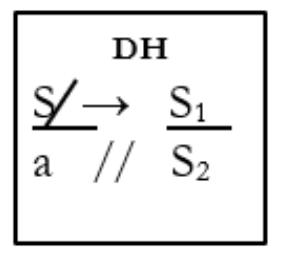

Para sermos ainda mais precisos, poderíamos dizer que estas críticas seriam antes a forma como estas ideologias, sustentadas no discurso histérico, puderam apreender este dispositivo. Não nos parece casual o fato de que, justamente no momento em que a psiquiatria biologicista encontra-se em plena ascensão, quando a objetificação do paciente pode ser sentida, tanto nas apresentações de paciente de cunho estritamente didático quanto no pragmatismo de suas intervenções medicamentosas, é que se dá a eclosão desses movimentos de inspiração humanista. Se podemos dizer então, de uma psiquiatria agenciada, prioritariamente, pelo discurso histérico, contudo não podemos dizer de apresentações de pacientes orientadas a partir deste discurso, pois isso seria totalmente incoerente. Neste discurso, o psiquiatra irá abordar a loucura se posicionado enquanto sujeito dividido (\$), angustiado, que interroga o mestre $\left(\mathrm{S}_{1}\right)$, questionando o saber estabelecido e suas práticas, dentre as quais, a apresentação de paciente. Quanto ao louco, no lugar do Outro $\left(S_{1}\right)$, este é tomado imaginariamente como sendo um sujeito-cidadão, portanto, senhor de si, desconhecendo-se assim, sua dimensão inconsciente de gozo.

Essa psiquiatria trata o paciente como um sujeito de direito $\left(\mathrm{S}_{2}\right)$, um cidadão, cuja diferença deve ser respeitada, acolhida, reintegrada à sociedade. Porém, elaborado imaginariamente, esse saber $\left(S_{2}\right)$ ignora o saber do próprio sujeito. Por acreditar poder compreender o paciente, o psiquiatra/profissional da saúde mental se coloca como aquele que sabe das necessidades do paciente, que sabe o que é bom para ele. Mas a verdade oculta do discurso histérico é que o psiquiatra/profissional da saúde mental se faz ser aquilo (a) que falta ao Outro para, por um lado, completá-lo, e, por outro, tornar-se indispensável. Contudo, na medida em que o saber produzido se faz disjunto da verdade (a// $\left.\mathrm{S}_{2}\right)$, trata-se de um saber que não se articula ao gozo. Assim, o psiquiatra se defronta com a impossibilidade de fazer o paciente desejar aquilo que é considerado melhor para ele. E por desconhecer a dimensão de gozo, o profissional da saúde mental não reconhece, nem a implicação do paciente (\$) sujeito em seu sofrimento, nem o seu próprio gozo diante da impotência de salvar o paciente de si mesmo. Sobre a apresentação de pacientes, podemos dizer então que, para a perspectiva humanista, esta se torna uma prática absurda, condenável: um desrespeito, uma violência contra seus direitos de cidadão, uma exposição da qual o paciente não retiraria qualquer benefício.

Contudo, essa leitura se equivoca ao desconsiderar que há, para além do cidadão, da pessoa, um sujeito do inconsciente. Sujeito que, na psicose, como nos diz Miller, é precisamente um sujeito exposto: "Seus distúrbios se restringem precisamente ao fato de que, na esfera mais íntima de sua cogitação, mesmo nas partes de sua própria anatomia, ele é invadido por uma presença" (MILLER, 2008, p. 55).

Assim, a presença da platéia, ao contrário do que poderia parecer inicialmente, não tem, para o psicótico, um efeito de exposição, mas, antes, de regulação do Outro. Afinal, a presença do público parece favorecer ao psicótico a localização do Outro num terceiro, diminuindo a tensão da relação especular com o apresentador, o que frequentemente tem efeito apaziguador para o paciente.

Por fim, podemos dizer com Miller sobre a apresentação, que "o paciente testemunharia que ela Ihe saber ser benéfica, tanto pelo acesso à palavra que por vezes lhe proporciona, como pela apreciação mais justa de seu caso que daí decorre o mais frequentemente" (MILLER, 1996, p. 141). E é exatamente isso que podemos recolher com alguma freqüência nas falas de pacientes ao final de uma apresentação: “Gostei muito 
de dar essa palestra", "Obrigado por me escutarem"2, ou "Eu não tenho com quem conversar e vocês me escutaram. Obrigado por terem me escolhido" 3 (Paciente apresentado em 21 de maio de 2013).

\section{CONSIDERAÇÕES FINAIS}

Por fim, para concluir, é preciso considerar a apresentação de pacientes na contemporaneidade, analisando os efeitos que sobre ela tiveram o Discurso Capitalista. Segundo Lacan, este discurso, resultado de uma variante do discurso do mestre, seria o laço social dominante em nossa sociedade atual.

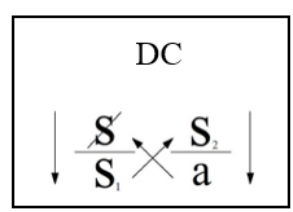

Comandado pelo S1, capital, esse é um discurso que, em lugar de favorecer o laço social entre os homens, favorece que os sujeitos se relacionem, sobretudo, com os objetos de consumo, efeito da multiplicação destes. A ascensão do discurso capitalista incide sobre todas as áreas de nossa vida. Os avanços da tecnologia, da ciência, da comunicação, o acesso à informação e à pesquisa, os bens de consumo, dentre outros aspectos da cultura, estão diretamente ligados a ele, sendo transformados em mercadoria que o sujeito-consumidor anseia em ter.

De certo que este discurso também tem impacto sobre a psiquiatria. É preciso marcar, inicialmente, que a psiquiatria está cada vez mais articulada aos "avanços da ciência", que, por sua vez, também é comandada pelo discurso capitalista. Assim, tanto a neurociências quanto a psicofarmacologia, que apresentam grande afinidade com o discurso capitalista, se prestam a transformar doença e medicação em produtos de consumo. O que podemos testemunhar é a sobreposição da lógica de mercado ao campo da saúde. Temos assim que, no lugar da verdade, encontra-se o capital $\left(S_{1}\right)$ e como agente, temos o sujeito reduzido a consumidor $(\$)$ de gadgets (a), produzidos pela ciência e tecnologia $\left(\mathrm{S}_{2}\right)$, que, no caso da saúde, seriam justamente os transtornos e suas respectivas medicações, produzidos pelas neurociências e pela indústria farmacêutica. Essa medicina de mercado nos faz interrogar, como propõe Quinet, se essa evolução da ciência "produz novos remédios para novos 'males', ou ela produz os 'males', pseudo novos males, para que sejam tratados pelos medicamentos que ela produz?" (QUINET, 2006, p. 22).

Quanto à apresentação de pacientes, poderíamos dizer que esta também sofre os efeitos desse discurso. Aqui, só podemos apresentar algumas conjecturas. Embora as apresentações continuem ocorrendo nas instituições de tratamento, o que podemos ver é que a apresentação de pacientes tem ganhado novos contornos. Como acontece com tudo aquilo sobre o qual o discurso capitalista incide, também a apresentação vem sendo transformada em um objeto de consumo. Todavia, ela aparece descaracterizada, pois é retirada do ambiente restrito do campo da saúde para se transformar num gadget da mass media. Se antes a função de apresentador era prerrogativa do especialista da saúde, agora o essencial é que este seja um entertainer, capaz de conduzir seja um programa de auditório, seja uma reportagem. Nestes programas, os pacientes são convidados a falar de seus sintomas ao público leigo - os espectadores, ávidos por identificações. Assim, paciente e público podem se igualar enquanto vítimas das alterações neuroquímicas, cúmplices da desimplicação do sujeito em seu mal-estar. Quanto ao apresentador, portador das boas novas, este tem a

\footnotetext{
2 Tomamos, como referência, um trabalho de seis anos com a prática de apresentações de pacientes (1999 a 2005) no Instituto Raul Soares, em BH/MG, no qual aconteciam, regularmente, dois espaços de discussão clínica: o Núcleo de Pesquisa em Psicose IPSM-MG em parceria com o IRS; e a Sessão Clínica do IRS (2000 a 2005). Ambos espaços de orientação psicanalítica, sendo as entrevistas realizadas por analistas da EBP-MG.

${ }^{3}$ Relato do paciente apresentado no Núcleo de Pesquisa em Psicose - IPSM-MG, em parceria com a Prefeitura de Belo Horizonte (PBH).
} 
função de revelar as maravilhas que a ciência pode oferecer para confirmar seu diagnóstico e, quem sabe, até aliviar seu sofrimento.

Por fim, para concluir, podemos ressaltar que proceder a essa análise a partir da conjunção entre dispositivo e discurso nos permitiu deslocar a ênfase da discussão sobre a pertinência ou não do uso do dispositivo, para situá-la em suas verdadeiras bases, a saber, da eficácia de cada discurso para lidar com o real e jogo na loucura.

Contudo, é preciso situar que não se trata de uma questão sobre quem tem a verdade, afinal, como nos diz Rabinovich: "Nenhum desses discursos é 'a verdade"” (RABINOVICH, 2001, p. 13), pois, a verdade, enquanto lugar, está presente em cada um deles, não sendo os efeitos da apresentação, mais do que os efeitos de sua produção, que sempre lhe aparece disjunta.

Recebido em: 9 de janeiro de 2017, Aprovado em: 17 de agosto de 2017.

\section{REFERÊNCIAS}

BARRETO, F. S ou a síndrome do automatismo mental, de Clérambault. In: OLIVEIRA, R. (org.). Seminários em Psicopatologia: da psiquiatria clássica à contemporaneidade. Belo Horizonte: Coopmed, 2013.

BENETI, A. () Sobre a apresentação de Enfermos. Opção Lacaniana - Revista Brasileira Internacional de Psicanálise. São Paulo: Edições Eólia, n. 11, 1994, p. 93-96.

CLERAMBAUlT, G. G. de. Automatismo mental: paranóia (1942). Buenos Aires: Polemos, 2004.

FERREIRA, A. O ensino da psicopatologia: do modelo asilar à clínica da interação. Revista latinoamericana de psicopatologia fundamental. São Paulo, ano V, n. 4, 2002, p. 11-20.

FERREIRA, C. Apresentação de pacientes: dispositivo e discursos. Tese de Doutorado, Programa de pósgraduação em Estudos Psicanalíticos, Universidade Federal de Minas Gerais, Faculdade de Filosofia e Ciências Humanas, 2013.

Apresentação de pacientes: (re)descobrindo a dimensão clínica. Dissertação de Mestrado, Programa de Pós-graduação em Estudos Psicanalíticos, Universidade Federal de Minas Gerais, Faculdade de Filosofia e Ciências Humanas, 2006.

FOUCAULT, M. A casa dos loucos. In: Microfísica do poder. Rio de Janeiro: Edições Graal, 1979.

. O poder psiquiátrico (1973-1974).. São Paulo: Martins Fontes, 2006.

GURGEL, I. (Relator). A moça que sofria: do bicho ao sujeito. In: I/ Encontro Americano do Campo Freudiano: os resultados terapêuticos da psicanálise. [CD-ROM]. Buenos Aires, 2006.

HOUAISS, A. Dicionário eletrônico Houaiss da língua portuguesa. São Paulo: Objetiva, 2001.

LACAN, J. De uma questão preliminar a todo tratamento possível da psicose (1957-1958). In: Escritos. Rio de Janeiro: J. Zahar, 1998a.

\section{$\overline{1998 b .}$}

Formulações sobre a causalidade psíquica (1946). In: Escritos. Rio de Janeiro: J. Zahar,

. O avesso da psicanálise (1969-1970). Rio de Janeiro: Jorge Zahar, 1992. (O seminário, 17).

O peor... (El saber de psicoanalista). In: Obra de Jacques Lacan, [CD-ROM]. Folio Views, 1972. (El seminário, 19).

LAURENT, E. A apresentação de pacientes. Clínica Lacaniana: publicação de Psicanálise da Biblioteca Freudiana. Srf. n. 3, 1989, p. 149-187.

LÉGER, C. Elogio de la presentación de enfermos: un dispositivo adecuado. In: MILLER, J-A. et al. Los classificables de la clínica psicoanalítca. Buenos Aires: Paidós, 2008.

LEGUIL, F. La experiencia enigmática de la psicosis en las presentaciones clínicas. L-ment@I: principios para una formación posible en la presentación de enfermos. Bogotá, Edición, n. 1, 2004, p. 44-47.

. Sobre as apresentações clínicas de Jacques Lacan. In: GIROUD, F. et al. Lacan, você conhece? São Paulo: Cultura Editores, 1998.

MILLER, J-A. Lições sobre apresentações de doentes. In: Zahar Editor, 1996. Matemas I, Rio de Janeiro: Jorge 
MILLER, J-A. et al. El conciliábulo de Angers. In: (org.). Los classificables de la clínica psicoanalítca Buenos Aires: Paidós, 2008.

MOURA, M. C. M. Os discursos: mestre, histérica e capitalista. Cadernos. A escrita de Jacques Lacan: matemas, esquemas grafo, a lógica e topologia. Belo Horizonte: Aleph, n. 1, 2010, p. 53-71.

PESSOTTI, I. O século dos manicômios. São Paulo: Editora 34, 1996.

PORGE, E. A apresentação de doentes. In: Boletim Novidade da Pulsional. São Paulo, n. 87, 1996, p. 19-40.

Apresentação de paciente: uma clínica da apresentação. In: Transmitir a clínica psicanalítica: Freud, Lacan, hoje. Campinas: Ed. Unicamp, 2009, p. 223-235.

QUINET, A. Psicose e laço social: esquizofrenia, paranóia e melancolia. Rio de Janeiro: Jorge Zahar, 2006.

RABINOVICH, D. O psicanalista entre o mestre e o pedagogo. Cadernos de psicologia. Belo Horizonte, n. 11, 2001, p. 9-28.

RODRIGUES, G. V. A psicanálise pelo avesso: uma leitura do seminário O Avesso da Psicanálise livro 17 de Jacques Lacan. Belo Horizonte: Ophicina da arte \& prosa, 2010.

SALIM, J. Noções de psicofarmacoterapia na prática. São Paulo: EPU: EDUC, 1987.

SANTIAGO, J. Nota sobre o fundamento clínico da apresentação de enfermos. Curinga EBP/MG, n. 14, 2000, p. 80-83.

\section{Cristiana Miranda Ramos Ferreira}

Doutora pelo Programa de Pós-Graduação em Psicologia, (área de concentração Estudos Psicanalíticos), Universidade Federal de Minas Gerais (UFMG), Belo Horizonte/MG, Brasil, cris.ramos.bhz@gmail.com

Jesus Santiago

Professor Aposentado do Departamento de Psicologia, Programa de Pós-Graduação em Psicologia, Universidade Federal de Minas Gerais (UFMG), Belo Horizonte/MG, Brasil, santiago.bhe@terra.com.br 